\title{
Pesquisa em rede em aquicultura: bases tecnológicas para o desenvolvimento sustentável da aqüicultura no Brasil. Aquabrasil
}

\author{
Emiko Kawakami de Resende ${ }^{1}$ \\ ${ }^{1}$ Embrapa Pantanal - Rua 21 de Setembro, 1880 - CEP: 79320-900 - CEP: Corumbá, MS.
}

RESUMO - O projeto Aquabrasil pretende promover um salto tecnológico na aqüicultura brasileira ao atender às principais demandas da cadeia produtiva aquícola, especialmente na obtenção de alevinos de boa qualidade via melhoramento genético. Utilizando alevinos geneticamente melhorados, com manejo e gestão ambiental associado a boas práticas de manejo, oferecendo alimentos nutricionalmente balanceados, em consonância com os hábitos alimentares de cada espécie e promovendo a identificação e o controle sanitário será possível produzir matéria prima de alta qualidade, passível de processamento agroindustrial capaz de atender tanto ao mercado interno como externo. Participam do projeto Aquabrasil mais de 70 pesquisadores pertencentes a onze unidades de pesquisa da Embrapa e uma série de unidades estaduais e federais, órgãos de pesquisa estaduais e uma série de empresas privadas. Na sua gestão conta com um Conselho Consultivo, formado por órgãos governamentais afetos ao assunto e com a participação da iniciativa privada. A árvore hiperbólica, sistema desenvolvido pela Embrapa, possibilita a gestão do projeto em tempo real.

Palavras-chave: boas práticas de manejo e aproveitamento agroindustrial, cadeia produtiva, melhoramento genético, nutrição, sanidade

\section{Research in network in aquaculture: technological basis for sustainable development of aquaculture in Brazil. Aquabrasil}

\begin{abstract}
The project aims at giving a technological upgrade to Brazilian aquaculture to attend the demands of the productive chain. The research focus in obtaining genetically improved fishes; in developing environmental friendly feeds of high zootechnical performance; and in implementing the integrated sanitary control in production systems. The adoption of "Best Management Practices" (BPMs) in aqualcuture systems will assure the production of good quality fishes and shrimps with higher market prices. The AQUABRASIL project involves more than 70 researchers of eleven different Embrapa research units spread over all the country, national and international research institutes and professors from several public and private universities. An Advisory Council with members from public financial institutions and private sector has a mission to follow, to assess and to publicize the results of the project. A system developed by Embrapa, known as "árvore hiperbólica" is the way to get on time management of the project.
\end{abstract}

Key Words: best management practices, fish health, genetic improvement, nutrition, productive chain

\section{Introdução}

O projeto "Bases tecnológicas para o desenvolvimento sustentável da aqüicultura no Brasil - Aquabrasil”, está estruturado para atender ao objetivo estratégico da Embrapa de contribuir para a modernização das cadeias produtivas aquícolas, promovendo avanços científicos e tecnológicos, sanitários e ambientais que viabilizem a agregação de valor a produtos aquícolas nacionais bem como para o desenvolvimento de conhecimentos, tecnologias e processos que contribuam para a superação dos desequilíbrios regionais e o uso eficiente de recursos (Queiroz et al., 2002). Está na linha dos projetos de pesquisa para a solução dos grandes desafios nacionais, pois o Brasil, com a sua dimensão territorial, a maior diversidade ictiológica do mundo e a disponibilidade de recursos hídricos que possui ainda é importador de pescado para atendimento à demanda nacional. (Borghetti et al., 2003).

O projeto Aquabrasil foi idealizado com muito esforço, justamente para produzir o salto tecnológico na aqüicultura brasileira que possa preencher o déficit de produção vigente e dentro de uma visão de cadeia produtiva que abranja do produtor ao consumidor. O que seria essa visão de cadeia produtiva? Para que o produto final, o pescado, chegue em quantidade e qualidade na mesa do consumidor, acreditamos que os seguintes passos necessitam ser dados: 
1 - ter acesso a alevinos de qualidade;

2 - ter acesso a alevinos que sejam saudáveis e que sejam criados de forma saudável;

3 - o alimento/ração a ser fornecido para todas as etapas do seu crescimento até o abate deve atender às exigências nutricionais de cada uma das etapas de desenvolvimento e com um mínimo de eliminação ao ambiente e que seja economicamente viável;

4 - devem ser criados em sistemas onde as condições sejam as melhores possíveis;

5 - ao chegar ao processamento devem apresentar as melhores características sanitárias possíveis para assegurar produtos de qualidade ao consumidor;

6 - Todas as etapas do processo devem ser equacionadas de forma a causar o menor impacto ambiental possível.

7 - Direcionar os esforços para espécies prioritárias, em termos nacionais e regionais.

Estes enunciados implicam no desenvolvimento de projeto que contemple aspectos como melhoramento genético, nutrição, sanidade, manejo e gestão ambiental e aproveitamento agroindustrial e a eleição de espécies prioritárias.

As Figuras 1 e 2 ilustram o esquema utilizado.

Os programas de melhoramento genético, efetuados com animais e plantas têm sido o alicerce do desenvolvimento agropecuário. Embora existam muitas iniciativas de criação de organismos aquáticos no Brasil, este ocupa uma modesta $19^{a}$ posição de produção em nível mundial (Borghetti et al., 2003). Dentre as espécies cultivadas para exportação, destacam-se a tilápia (Oreochromis niloticus) e o camarão marinho, Litopenaues vannamei (Borghetti et al., op. cit.).

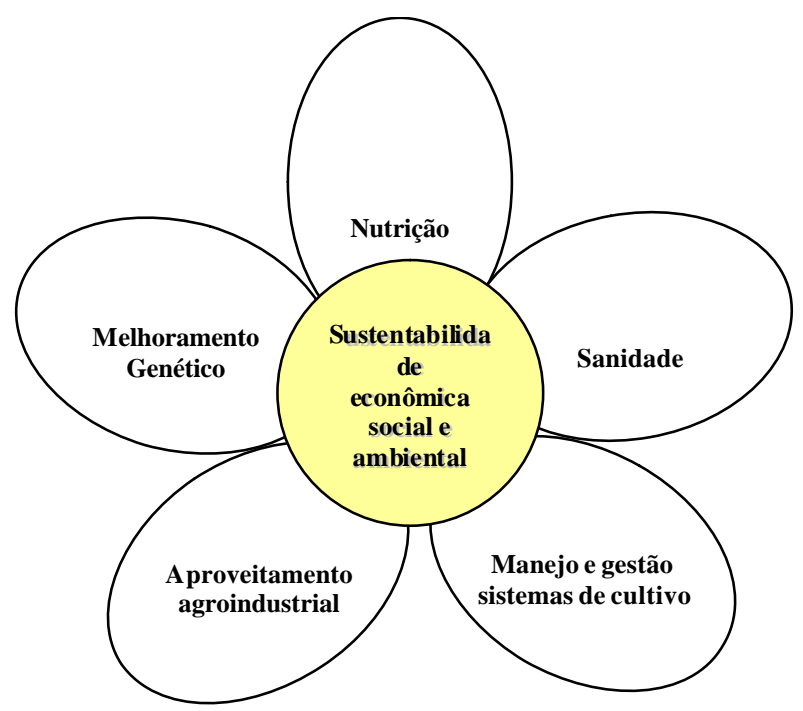

Figura 1 - Esquema representativo dos projetos componentes envolvidos para alcançar a sustentabilidade da atividade aquícola.
Considerando-se o potencial de cultivo de espécies nativas, verifica-se que há uma grande aceitação regional do tambaqui (Colossoma .macropomum), criado na região norte (Melo et al., 2001; Izel \& Melo, 2004) e do pintado (híbridos do gêneroPseudoplatystoma) na região centrooeste (Gontijo et al., 2005). Entretanto, essas produções regionais, com exceção do camarão marinho e da tilápia GIFT, recentemente introduzida no Brasil a partir da Malásia, trabalham com o potencial genético silvestre, sem nenhum melhoramento. Por falta de alternativas e querendo ser competitivos, os produtores de tambaqui e pintado desenvolveram híbridos inter-específicos, sem nenhuma informação acerca do seu possível retrocruzamento com os parentais nativos caso escapem para a natureza. A experiência com algumas espécies aquáticas (tilápia, salmão, carpas) mostra que o melhoramento genético na taxa de crescimento pode proporcionar ganhos de cerca de $15 \%$ por geração em programas bem conduzidos (Ponzoni et al. 2005). A introdução da tilápia GIFT (Genetically Improved Farming Tilapia) no Brasil, em 2005, através da Universidade Estadual de Maringá, bem como o treinamento oferecido à época constitui o marco inicial através do qual se pretende estender esses mesmos objetivos para espécies prioritárias ao Brasil em termos de exportação e para consumo local, funcionando a UEM como entidade nucleadora, ao tempo em que será continuado o melhoramento dessa tilápia e implementados programas de melhoramento para o aumento na taxa de crescimento em tambaqui e pintado. No caso do programa de melhoramento para o camarão marinho, objetiva-se a obtenção de uma linhagem resistente a doenças, uma vez que esta é a principal demanda do setor produtivo, o qual tem enfrentado perdas de 40 a $70 \%$ em suas produções causadas pela mionecrose infecciosa. Ao final deste projeto de quatro anos, espera-se que tenham

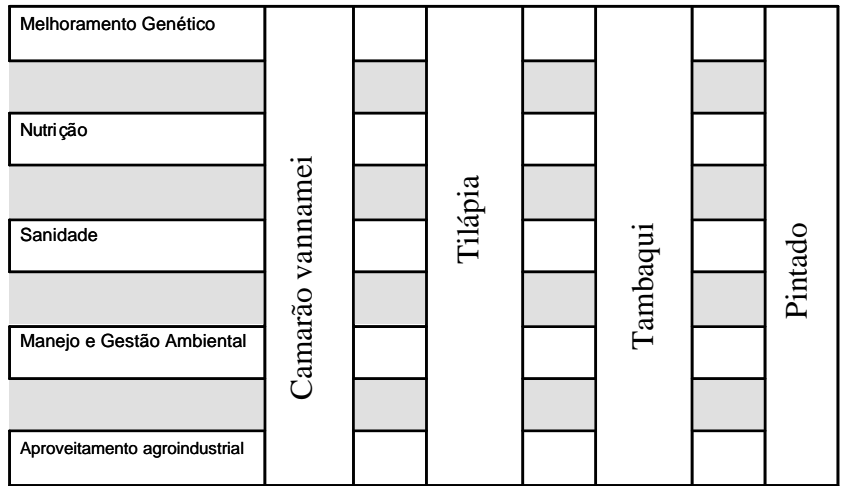

Figura 2 - Figura explicativa das interações entre os diversos componentes para alcançar a sustentabilidade e as espécies prioritárias objeto de pesquisa. 
sido obtidas gerações de tilápias melhoradas, linhagens de camarão marinho mais resistentes a doenças e criados os bancos iniciais de reprodutores para o melhoramento do tambaqui e pintado. Para estas duas últimas espécies, como o tempo de maturação reprodutiva é mais longo, o prazo previsto para a execução do projeto permitirá a criação da primeira geração do banco de reprodutores. Com este projeto em rede, será possível também o treinamento e a transferência de conhecimentos e tecnologias entre os vários pesquisadores das várias áreas do projeto, de todas as regiões do Brasil que estarão inseridos na proposta. Ao final, espera-se desenvolver uma massa crítica capaz de alavancar o desenvolvimento da aqüicultura no Brasil, com possibilidades de alcançar os mesmos resultados que hoje existem para a soja e a criação bovina. Espécies melhoradas poderão contribuir para a redução da aplicação de medicamentos para controle de doenças, melhoria na qualidade da água via redução de carga orgânica na água dos viveiros, via aproveitamento mais eficiente de ração formulada com base no conceito de proteína ideal, produção mais elevada sem aumento de espaço de cultivo, tornando a atividade mais competitiva e reduzindo os riscos de retrocruzamento de híbridos inter-específicos com os estoques nativos.

Os altos custos das rações, boas práticas de manejo alimentar e o difícil acesso a tecnologias inovadoras constituem obstáculos que colocam a piscicultura regional em uma situação de desvantagem em relação ao desenvolvimento da aqüicultura mundial. Pesquisas devem ser desenvolvidas utilizando ingredientes alternativos para reduzir custos de produção e aumentar a eficiência das rações de forma que sejam obtidas altas produtividades por área, minimizando o impacto ambiental. Na atualidade, a piscicultura de espécies nativas está em desvantagem em relação a de espécies exóticas devido, entre outras razões, à escassez de conhecimentos específicos sobre a nutrição que possam contribuir para a elaboração de rações de baixo custo que respondam as exigências nutricionais das espécies cultivadas, bem como ao 'não-domínio' de boas práticas de manejo alimentar, que poderiam contribuir na otimização da produção. Uma alternativa para o aumento da eficiência de uma dieta comercial é a sua suplementação com aditivos, tais como probióticos, células microbianas, geralmente bactérias, mas também leveduras, suplementadas ainda vivas na ração ou na água, com o propósito de colonizar o trato gastrintestinal, melhorando a saúde e gerando aumento da qualidade do pescado (Gatesoupe, 1999). Entretanto, para justificar o aumento do custo da ração e a mão de obra envolvida na adição de probióticos em rações comerciais, estes devem também promover um aumento significativo no ganho em peso dos peixes. Até o presente, as cepas de bactérias e leveduras probióticas disponíveis no mercado são importadas e sua eficácia não é comprovada nas condições de cultivo nacional. Desta forma, o desenvolvimento de probióticos isolados diretamente do trato digestivo dos organismos no ambiente de cultivo ou mesmo em ambientes mais poluídos, apresenta-se como uma alternativa para aumentar a eficácia destes produtos. Igualmente, o desenvolvimento de tecnologia para aplicação de probióticos nas rações comerciais é fundamental para a viabilização desta prática nas fazendas. Com a incidência do vírus da mancha branca no Brasil, faz-se necessário o estudo de alternativas para melhorar a saúde do camarão. O policultivo do camarão branco com a tilápia parece ser uma alternativa viável e que já é adotada por países que enfrentaram sérios problemas com o aparecimento do vírus da mancha branca, tal como o Equador. Além disso, o uso de probiótico também será estudado na alimentação do tambaqui, com objetivos produtivos e de saúde. Desta forma, são propostas ações para melhorar a saúde e o desempenho da tilápia, do tambaqui e do camarão marinho, as quais poderão também servir de subsídio para condições de policultivo. É sabido que o uso de ácidos graxos poliinsaturados da série $n-3$, pode reduzir o estresse na larvicultura, sendo uma ótima opção a ser testada com o pintado a fim de reduzir a mortalidade neste estádio do desenvolvimento. A susceptibilidade dos peixes ao estresse e a considerável disseminação de patógenos têm sido uma preocupação constante dos piscicultores que buscam obter uma produção de peixes saudáveis e, como resultado, um desempenho econômico sustentável. É importante desenvolver técnicas para evitar transtornos à saúde dos peixes cultivados. Todavia o desenvolvimento de tais técnicas passa pela necessidade do diagnóstico da situação epidemiológica e sanitária dos estabelecimentos de cultivo para que se possa interferir de forma eficiente no processo, ampliando pesquisas conjuntas na área de patologia, imunologia e imunonutrição, melhoramento genético e manejo dos ambientes de cultivo de peixes usados na alimentação humana.

A intensificação nos sistemas de produção de organismos aquáticos tem revelado obstáculos que afetam diretamente a produtividade e o crescimento da atividade, estando a área de Sanidade como um dos principais entraves e que proporciona a base para o estudo e desenvolvimento de novas tecnologias. Altas densidades, manejo inadequado, deficiências nutricionais e variações nas características físico-químicas da água favorecem a 
quebra no equilíbrio do sistema hospedeiro/patógeno/ ambiente. Sob condições ambientais adequadas e baixa resistência do organismo cultivado, ocorre a proliferação do patógeno, muitas vezes oportunista, culminando em mortalidades e perdas econômicas. A utilização de formas alternativas de prevenção e viáveis aumenta a resistência do animal frente às adversidades ambientais ou na presença de patógenos ou organismos oportunistas. Esta é a visão responsável e ecologicamente mais correta, reduzindo o uso indiscriminado de antibióticos e quimioterápicos. A incorporação desta nova visão no sistema de produção melhora o desempenho e a capacidade de resposta do organismo frente àqueles fatores estressantes. No entanto, a falta de um monitoramento regular dos animais na criação, de orientação de produtores e empresários, profissionais e técnicos, releva a importância do diagnóstico parasitológico, histopatológico e hematológico ou de hemolinfa em peixes e crustáceos cultivados. Dessa forma, a validação do estado sanitário dos organismos utilizando como ferramentas os diferentes métodos de diagnóstico, a utilização de agentes imunoestimulantes, bem como a difusão de conhecimento para as diferentes partes envolvidas no processo e a integração com outros componentes como nutrição, manejo do ambiente de cultivo e o uso de linhagens melhoradas, bem como entre os pesquisadores das instituições participantes, poderá resultar em ganho produtivo para a atividade.

Um dos grandes questionamentos sobre a aqüicultura é a falta de métodos eficazes para reduzir seus impactos ambientais e socioeconômicos, e também como as leis de proteção ambiental em vigor poderão contribuir de forma efetiva para o seu desenvolvimento (Boyd et al., 2003). A produção de organismos aquáticos muitas vezes é considerada como causadora de impactos ambientais negativos por consumir recursos naturais, ocasionar poluição e interferências em níveis de biodiversidade e também, por estar diretamente ligada a um recurso de múltiplos usos e essencial para a vida: a água (Tiago, 2007). As cadeias produtivas da tilápia, tambaqui, pintado e camarões marinhos que serão estudadas e avaliadas pelo projeto se destacam entre as mais importantes da aqüicultura brasileira. Entretanto, ainda é preciso concentrar esforços em pesquisa e desenvolvimento para reduzir os entraves que estão prejudicando a sua sustentabilidade, tais como: baixa qualidade do material genético dos alevinos e das pós-larvas; baixa competitividade com relação a outras indústrias de carne; alto custo e qualidade das rações; duplicidade e falta de direcionamento das pesquisas; baixo desempenho sócio ambiental e econômico da cadeia produtiva da aqüicultura e entraves causados por uma legislação ambiental muito restritiva (Queiroz et al., 2002). Em geral, a aqüicultura não tem sido considerada no planejamento nacional relacionada à conservação do solo e da água, poluição da água, programas de quarentena de plantas e animais, e outros aspectos do manejo ambiental. É necessário buscar soluções para consolidar o desenvolvimento sustentável da aqüicultura com foco na otimização do manejo dos sistemas de produção selecionado a partir de um envolvimento transdisciplinar e integrado com os demais aspectos inerentes à produção (genética, nutrição, sanidade) a fim de desenvolver e validar boas Práticas de Manejo (BPMs). Parte-se do pressuposto de que grande parte dos impactos ambientais pode ser evitada ou minimizada pela adoção de Boas Práticas de Manejo (BPMs). Nesse sentido, a partir da execução compartilhada (participativa) e multidisciplinar das ações de pesquisa desenvolvidas para cada um dos temas-estudos do projeto e no âmbito de cada um dos Projetos Componentes (PCs), pretende-se: a) selecionar um conjunto de indicadores físico-químicos e biológicos de qualidade da água e de sedimentos para otimizar a gestão ambiental dos sistemas de produção aqüícola, a fim de reduzir a carga orgânica e os sólidos em suspensão dos efluentes, a disseminação de doenças e a contaminação por metais pesados, hormônios e pesticidas; b) contribuir para a preservação da biodiversidade e da biossegurança com base no biomonitoramento dos sistemas de produção; c) reduzir os impactos ambientais e otimizar os índices zootécnicos de produção a partir da introdução de melhorias no manejo nutricional e alimentar para as diferentes espécies conjugadas aos sistemas de cultivo selecionados com base no uso de bacias de sedimentação e de rações "ambientalmente corretas"; d) avaliar as relações entre os parâmetros físico-químicos e biológicos de qualidade da água causadores de estresse e doenças com os índices de produtividade, resistência a doenças e redução no uso de terapêuticos, e o rendimento de ganho em peso em cultivos com espécies melhoradas geneticamente; e) identificar e selecionar um conjunto de categorias e variáveis que vincule a estrutura produtiva com o seu desempenho competitivo a fim de avaliar e comparar o nível de competitividade e eficiência entre as cadeias produtivas das diferentes espécies, buscando-se relacionar as variáveis ambiental e econômica com a sustentabilidade a longo prazo destas cadeias; e f) favorecer a organização, recuperação e disseminação de informações que subsidiem a gestão ambiental da aqüicultura e a elaboração de protocolos de 
Boas Práticas de Manejo (BPMs), imprescindíveis para o planejamento ambiental da aqüicultura com foco em sua sustentabilidade, e ao acesso do produtor à orientações de manejo correto do sistema produtivo voltadas à redução de impactos ambientais negativos.

A qualidade da matéria-prima é o ponto chave para a qualidade do produto. O manejo adequado visando a qualidade da água e a combinação dos fatores de produção que levem à obtenção do pescado em bom estado higiênicosanitário, permitirá a obtenção do pescado in natura que, uma vez rastreado, poderá apresentar conformidade com a legislação e ser certificado como um alimento seguro. É paradoxal a relação entre a profícua aqüicultura brasileira e a tímida comercialização de pescado qualificado. O beneficiamento de pescado é um dos principais gargalos da cadeia produtiva aquícola, fazendo com que os produtores vendam seus produtos in natura sem qualidade e sem agregação de valor. De forma geral, o processamento de pescado no Brasil resume-se ao resfriamento ou congelamento sem critérios de poucas espécies visando a distribuição e comercialização. Dentro desse contexto, o presente projeto propõe a qualidade total na aqüicultura, a partir do pescado in natura e o desenvolvimento de técnicas para o beneficiamento de novos produtos, que levarão a um grande avanço na oferta de produtos com valor agregado. O desafio está em vencer a alta perecibilidade do pescado através de adoção de métodos de conservação e ao mesmo tempo, preservar o excelente valor nutritivo deste alimento, bem como otimizar o aproveitamento do pescado destinando o resíduo à obtenção de subprodutos que possam aumentar a receita da beneficiadora. Uma vez que o projeto em rede visa a sustentabilidade da aqüicultura no Brasil, o projeto componente de aproveitamento agroindustrial das espécies cultivadas insere-se nesse contex to de qualidade da água (manejo, gestão ambiental), qualidade do pescado (sanidade, fatores genéticos) e qualidade do produto (resultante das boas práticas em toda a cadeia, seguro ao consumidor, conveniente, com características sensoriais esperadas e nutritivo)

As pesquisas realizadas de forma tradicional não serão capazes de, em curto prazo, melhorar a produção aquícola do Brasil. O enfoque em rede e a integração dos pesquisadores das diferentes instituições alinhando os melhores cérebros, potencializará os esforços e possibilitará o alcance dos objetivos em prazo mais curto. Esta forma de atuação vem sendo utilizada cada vez mais, com excelentes resultados para os grandes problemas estratégicos do país, onde certamente a aqüicultura é uma delas.
No Brasil ainda são incipientes as informações e tecnologias para suportar o desenvolvimento de uma aqüicultura sustentável, capaz de atender às demandas do mercado nacional e para exportação.A massa crítica de pesquisadores ainda é pequena e insuficiente para responder adequadamente às necessidades da atividade, considerando a grande gama de espécies nativas passíveis de cultivo. Nesse sentido, para assegurar a remoção dos entraves ao desenvolvimento da aqüicultura no Brasil, é proposto um projeto para ser realizado em rede, de forma integrada, considerando espécies prioritárias e os principais problemas relacionados a cada uma delas, ao longo da cadeia produtiva. A qualidade da matéria - prima é o ponto chave para a qualidade do produto. O manejo adequado visando a nutrição e a qualidade da água e a combinação dos fatores de produção que levem à obtenção do pescado em bom estado higiênico-sanitário permitirá, por exemplo, a obtenção do pescado in natura que, uma vez rastreado e em conformidade com a legislação, poderá ser certificado como um alimento seguro e oferecido para o mercado interno e externo. No caso particular da tilápia, a continuidade do melhoramento da tilápia GIFT, introduzida da Malásia, melhorada no Brasil e ofertada aos produtores, na medida da produção dessas linhagens, aliadas ao fornecimento de rações de alto desempenho e baixo impacto ambiental, testada em conformidade com as linhagens melhoradas, com o diagnóstico das enfermidades e medidas profiláticas adequadas, e em sistemas de produção que atendam às boas práticas de manejo, certamente produzirá matéria prima de qualidade, seguro e de alto rendimento. Ao mesmo tempo, a realização de pesquisas integradas e em rede, baseadas em espécies nativas de valor regional como o tambaqui e o pintado, propiciará o desenvolvimento de uma nova cultura de pesquisa capaz de enfrentar grandes desafios e produzir resultados relevantes em espaço de tempo mais reduzido.e estratégico para o desenvolvimento do setor aquícola no país. Em muitos casos, os usuários das informações e tecnologias serão parceiros do projeto, o que encurta e garante a transferência de informações e tecnologias em benefício da sociedade como um todo. Por último, considerando que o número de profissionais que atuam na área ainda é muito escasso para a dimensão do Brasil, a melhor forma encontrada e colocada no presente projeto é uma rede de instituições colocando à disposição as suas melhores inteligências e infra-estrutura e dentro de uma visão de cadeia produtiva. Contempla ainda a participação ativa da iniciativa privada, sobretudo 
considerando-se que as infra-estruturas disponíveis ainda não se mostram suficientes para o atendimento a todas as etapas do projeto.

Um projeto em rede não é apenas um conjunto de atividades que é desenvolvido pelas instituições participantes. Deve conter uma forma eficaz de comunicação e de integração das atividades. O projeto está dividido em projetos componentes, que por sua vez contém planos de ação e atividades. Em cada uma dessas fases há um líder/ responsável pela execução. Todos eles estão sob a supervisão do líder e vice-líder do projeto como um todo. Para agilizar a comunicação foi construída uma comunidade virtual na Embrapa denominada "CATIR", comunidade de aprendizagem, trabalho e inovação em rede,onde

Cada um dos projetos do Macroprograma 1- grandes desafios nacionais, tem um espaço próprio. Infelizmente, por uma série de razões, este espaço não está funcionando muito bem.
Para a gestão em rede foi construída a árvore hiperbólica Aquabrasil, onde as informações de todos os projetos componentes com os respectivos Planos de Ação e atividades serão colocados para acompanhamento em tempo real e agilizar a gestão.

Os projetos MP1, grandes desafios nacionais estão sujeitas à avaliação anual de desempenho formado por membros do Comitê Gestor de Programa (instancia máxima de avaliação estratégica da programação de pesquisa da Embrapa) e por membros externos à Embrapa, componentes do Comitê Técnico de Avaliação.

Para assegurar ainda a transparência necessária e a participação efetiva da iniciativa privada, o Projeto Aquabrasil tem um Conselho Consultivo (Figura 3) formado por entidades técnico-científicas governamentais como MCT/CTAgro, CNPq, SEAP, Finep e CNA, com a missão de acompanhar, avaliar e divulgar os resultados do projeto.

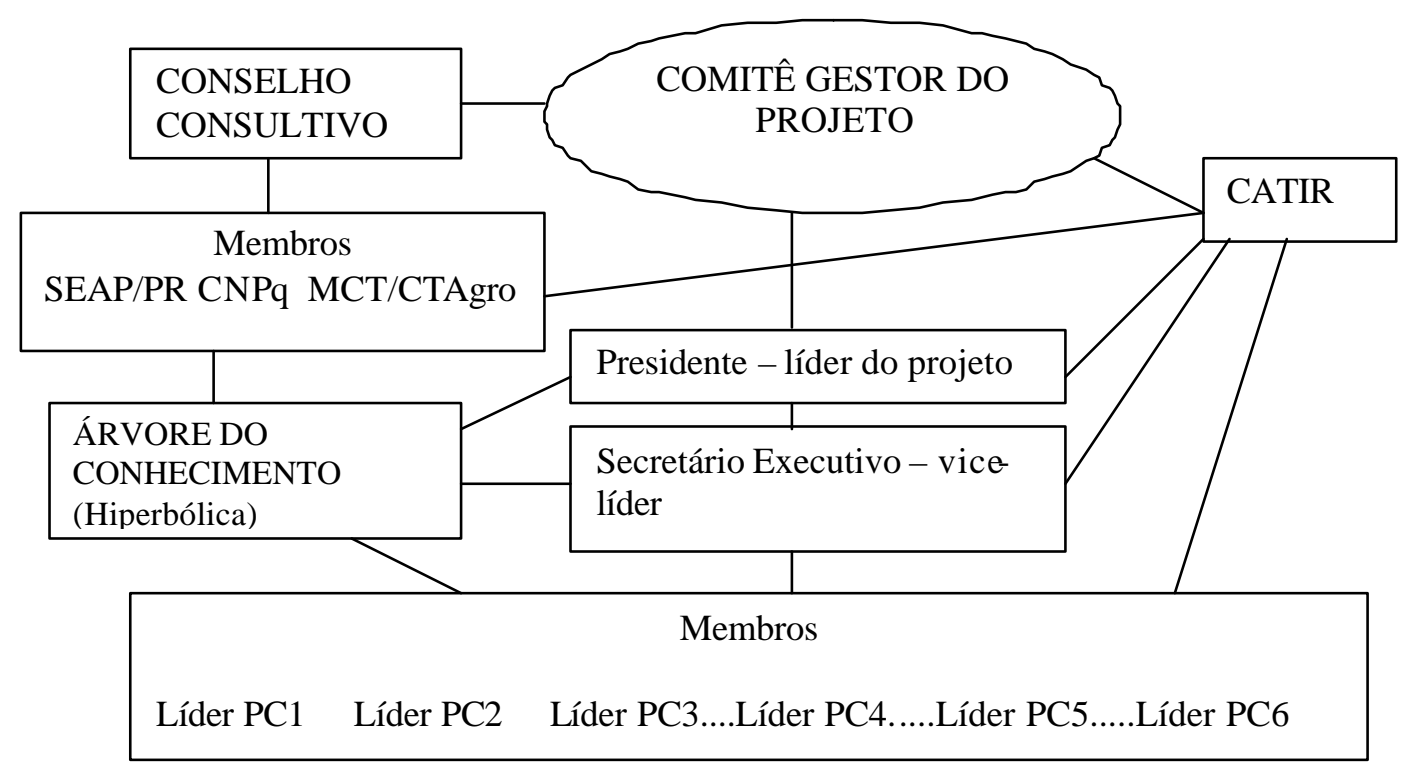

Figura 3 - Conselho consultivo do Projeto Aquabrasil.

\section{Literatura Citada}

BORGHETTI, N.R.B.; OSTRENSKY, A.; BORGHETTI, J.R. Aquicultura. Uma visão geral sobre a produção de organismos aquáticos no Brasil e no mundo. Curitiba: Grupo Integrado de Aqüicultura e Estudos ambientais, 2003. 128p.

BOYD, C.E.; QUEIROZ, J.F.; WHITIS, G.N. et al. Best management practices for channel catfish farming in Alabama. Montgomery: 2003. 38p. (Special Report $n^{\circ} 1$ For Alabama Catfish Producers).

GATESOUPE, F.J. The use of probiotics in aquaculture. Aquaculture, v.180, p.147-165, 1999.

GONTIJO, V. de P.M.; ISHIKAWA, M.M.; NOGUEIRA, L.S.; FORTES, W.G. Diagnóstico das pisciculturas do Programa Peixe Vida em Mato Grosso do Sul. Dourados: Embrapa Agropecuária Oeste, 2005. 36p. (Documentos, 69).
IZEL, A.C.U.; MELO, L.A.S. Criação de tambaqui (Colossoma macropomum) em tanques escavados no Estado do Amazonas. Manaus: Embrapa Amazônia Ocidental, 2004. 19p. (Documentos, 32).

MELO, L.A.S; IZEL, A.C.U.; RODRIGUES, F.M. Criação de tambaqui (Colossoma macropomum) em viveiros de argila/ barragens no Estado do Amazonas. Manaus: Embrapa Amazônia Ocidental, 2001. 30p. (Documentos, 18).

PONZONI, R.W.; HAMZAH, A.; TAN, S. et al. Genetic paramaters and response for live weigt in the GIFT strain of Nile tilapia (Oreochromis niloticus). Aquaculture, v.247, p.203-210, 2005.

QUEIROZ, J.F.; BERNARDINO, G.; CASTAGNOLLI, N. et al. A EMBRAPA e a Aquicultura: Demandas e Prioridades de Pesquisa. Cadernos de Ciências e Tecnologia. Brasília, DF: , No.11, p.1 35,2002 .

TIAGO, G.G. Aqüicultura, meio ambiente e legislação. 2.ed.rev. São Paulo: Gláucio Gonçalves Tiago (editor), 2007. 201p. 